\title{
Simulation-based low-dose, high-frequency plus mobile mentoring versus traditional group-based trainings among health workers on day of birth care in Nigeria; a cluster randomized controlled trial
}

Emmanuel Ugwa ${ }^{1 *}$, Mark Kabue ${ }^{2}$, Emmanuel Otolorin ${ }^{1}$, Gayane Yenokyan ${ }^{3}$, Adetiloye Oniyire ${ }^{1}$, Bright Orji ${ }^{1}$, Ugo Okoli', Joseph Enne', Gabriel Alobo', Gladys Olisaekee ${ }^{1}$, Adebayo Oluwatobi', Chioma Oduenyi', Adekunle Aledare ${ }^{4}$, Boniface Onwe ${ }^{5}$ and Gbenga Ishola ${ }^{1}$

\begin{abstract}
Background: The aim of this study was to compare health workers knowledge and skills competencies between those trained using the onsite simulation-based, low-dose, high frequency training plus mobile mentoring (LDHF/ m-mentoring) and the ones trained through traditional offsite, group-based training (TRAD) approach in Kogi and Ebonyi states, Nigeria, over a 12-month period.

Methods: A prospective cluster randomized controlled trial was conducted by enrolling 299 health workers who provided healthcare to mothers and their babies on the day of birth in 60 health facilities in Kogi and Ebonyi states. These were randomized to either LDHF/m-mentoring (intervention, $n=30$ facilities) or traditional group-based training (control, $n=30$ facilities) control arm. They received Basic Emergency Obstetrics and Newborn Care (BEmONC) training with simulated practice using anatomic models and role-plays. The control arm was trained offsite while the intervention arm was trained onsite where they worked. Mentorship was done through telephone calls and reminder text messages. The multiple choice questions (MCQs) and objective structured clinical examinations (OSCEs) mean scores were compared; $p$-value $<0.05$ was considered statistically significant. Qualitative data were also collected and content analysis was conducted.

(Continued on next page)
\end{abstract}

\footnotetext{
* Correspondence: drajulugreatgod@hotmail.co.za

'USAID's Maternal and Child Survival Program/Jhpiego, Nigeria, 971 Reuben Okoya Crescent, Wuye District, Abuja, Nigeria

Full list of author information is available at the end of the article
}

(c) The Author(s). 2020 Open Access This article is licensed under a Creative Commons Attribution 4.0 International License, which permits use, sharing, adaptation, distribution and reproduction in any medium or format, as long as you give appropriate credit to the original author(s) and the source, provide a link to the Creative Commons licence, and indicate if changes were made. The images or other third party material in this article are included in the article's Creative Commons licence, unless indicated otherwise in a credit line to the material. If material is not included in the article's Creative Commons licence and your intended use is not permitted by statutory regulation or exceeds the permitted use, you will need to obtain permission directly from the copyright holder. To view a copy of this licence, visit http://creativecommons.org/licenses/by/4.0/ The Creative Commons Public Domain Dedication waiver (http://creativecommons.org/publicdomain/zero/1.0/) applies to the data made available in this article, unless otherwise stated in a credit line to the data. 
(Continued from previous page)

Results: The mean knowledge scores between the two arms at months 3 and 12 post-training were equally high; no statistically significant differences. Both arms showed improvements in composite scores for assessed BEmONC clinical skills from around $30 \%$ at baseline to $75 \%$ and above at end line $(p<0.05)$. Overall, the observed improvement and retention of skills was higher in intervention arm compared to the control arm at 12 months post-training, $(p<0.05)$. Some LDHF/m-mentoring approach trainees reported that mentors' support improved their acquisition and maintenance of knowledge and skills, which may have led to reductions in maternal and newborn deaths in their facilities.

Conclusion: The LDHF/m-mentoring intervention is more effective than TRAD approach in improving health workers' skills acquisition and retention. Health care managers should have the option to select the LDHF/mmentoring learning approach, depending on their country's priorities or context, as it ensures health workers remain in their place of work during training events thus less disruption to service delivery.

Trial registration: The trial was retrospectively registered on August 24, 2017 at ClinicalTrials.Gov: NCT03269240.

Keywords: Training, Simulation, Mentoring, Health workers, Maternal and child health, Nigeria

\section{Background}

As there is limited number and quantity of skilled birth attendants in Nigeria, an evidence-based approach is needed to train health workers to improve competencies and maternal/newborn outcomes [1,2]. Doctors, nurses and community health extension workers (CHEWs) are commonly trained on day of birth care. Considering the high maternal and newborn mortality and morbidity figures in Nigeria, there is need to train birth attendants on high-impact interventions using competency-based approaches to improve the quality of maternal and newborn care and reduce maternal and perinatal/neonatal mortality [3-6]. It is expected that all health workers should be trained to the necessary level of competence to perform life-saving procedures on Basic Emergency Obstetric and Newborn Care (BEmONC) functions. These include newborn resuscitation and management of maternal bleeding after birth.

Despite continuous training of health workers, maternal and newborn health outcomes have remained suboptimal [7]. Health workers in Nigeria are usually trained using traditional lecture-based, offsite approach where limited number of health workers is trained from each facility at a time and the quality of care may not be improved to the desired level though the use of this approach [3]. Apart from the high cost of the offsite training approach [7-10], health workers' absenteeism from work to attend offsite training remains a concern for health facility managers $[9,10]$. In addition, health workers also find it difficult to practice new or updated skills because their colleagues at the facility have not received the same training on the relevant skills and approaches. In addition, step-down training by the few trained providers most often does not happen as intended due to lack of will, lack of time and management support among other factors. Moreover, health worker turnover, attrition and transfers also affects the quality of services particularly, when providers who have been trained are transferred out of the facility or when they leave by themselves.

Similar studies conducted is Ghana and Uganda $(7,8)$ showed promising results with the onsite simulationbased low-dose, high-frequency plus mobile mentoring training (LDHF/m-mentoring) approach. In these studies health workers' competencies were better with the LDHF/m-mentoring approach compared with the TRAD approach for skills assessed such as newborn resuscitation and postpartum haemorrhage $(\mathrm{PPH})$. The present study assessed additional skills such as active management of labour, management of eclampsia, and utilizes a more rigorous methodology in order to improve the strength of the evidence. A qualitative component is also included to triangulate the findings. There is limited evidence from developing countries including Nigeria on facilitators, barriers, and effectiveness of simulationbased LDHF/m-mentoring learning approaches in improving maternal and newborn health, including day of birth care. In the few studies where the LDHF/m-mentoring approach has been tested, sample sizes have been limited and methodological approaches have not been standardized [7]. The studies should be adequately powered and use rigorous designs to answer the research questions [7].

The LDHF/m-mentoring approach used in this study is described in the study protocol manuscript. This approach primarily involves simulation education, onsite, more interactive, and team-oriented training [11]. Simulation based medical education is an educational activity that utilizes simulation aids such as human anatomical models or manikins to replicate clinical case scenarios [12]. Simulations create opportunity for participants to improve competence through deliberate practice and serve as alternative to real case scenario especially for rarely practiced skills. In this instance, trainees may 
make mistakes and learn from them without the fear of injuries or harm to the patient [12].

\section{Methods \\ Study objectives}

The aim was to compare the knowledge and skills competencies of health workers in maternal and newborn care on day of birth after the LDHF/m-mentoring versus the TRAD training approaches in Ebonyi and Kogi states, Nigeria. The primary outcomes were increase in knowledge, clinical skills, and retention of clinical competency at 3- and 12months post-training. The secondary outcomes measured were facilitators of and barriers to the $\mathrm{LDHF} / \mathrm{m}$-mentoring training approach at individual and institutional levels.

Our hypothesis was that LDHF/m-mentoring (Group 1: intervention arm) results in better knowledge and skills outcomes compared to the TRAD approach (Group 2: control group).

\section{Study setting}

The study was conducted in Ebonyi and Kogi States, in Nigeria. Ebonyi State has a population of 2.8 million and is in the South-East zone. Kogi state has a population of 4.3 million and is in the North-Central zone. At the time of the study, the Maternal and Child Survival Program (MCSP), in partnership with the Federal Ministry of Health, Ebonyi and Kogi States Ministries of Health and Professional Associations supported 120 health facilities across the two states, of which 60 were selected to be part of the study, 30 in each state. The MCSP was a global, $\$ 560$ million, 5-year cooperative agreement funded by the United States Agency for International Development (USAID) to introduce and support scale-up of high-impact health interventions among USAID's 25 maternal and child health priority countries, as well as other countries.

\section{Study design}

This was a prospective cluster randomized controlled trial. It isa mixed- method study with quantitative and qualitative data collection approaches utilized. The study was conducted between October 2016 and November 2017 in sixty health facilities that were randomly selected and assigned to either the intervention arm or the control arm. A brief description of the methodology, the training approaches, eligibility criteria and randomization are provided; these are described extensively in the published study protocol [11].

Training approach 1 and data collection: simulation based LDHF/m-mentoring training of participants - group 1 or intervention group

As described by the authors in a previous study [11], the principles of the LDHF/m-mentoring approach include:
1. Competency-focused learning activities concentrates on what providers "need to know"-eliminating what is "nice to know."

2. Simulation- and case-based learning focuses on skills practice, problem-solving, role-play, and other interactive exercises. Dosing and frequency depend on topic, extent of the learning gaps, and learner characteristics.

3. Appropriately spaced, brief periods of learning deliver targeted information in 1 day or over several days.

4. Team-focused training ensures that all providers have updated clinical practice and can work together to implement improvements in care.

5. Facility-based training decreases absenteeism, improves teamwork, addresses onsite barriers, and promotes changes to provider performance.

6. Ongoing practice and quality improvement activities reinforce learning and transfer to clinical practice.

7. Facility-based peer staff, coaches others as they practice or engage in interactive exercises after learning to increase compliance and improve performance and outcomes.

\section{Consent}

Oral consent was obtained from the study participants prior to training and assessment (measurement).

\section{Training for group 1 LDHF/m-mentoring arm}

The training for group $1 \mathrm{LDHF} / \mathrm{m}$-mentoring arm was conducted for the entire team of health workers rendering maternal and newborn care at the health facility, but only those who met the study inclusion criteria were assessed. The training was divided into two "low-dose" training courses of four days each, with additional time for assessment as needed and was conducted at the health facilities using the BEmONC package. The BEmONC package include training on (i) administering parenteral antibiotics (ii) administering uterotonic drugs for active management of the third stage of labour and prevention of postpartum haemorrhage (iii) use of parenteral anticonvulsants for the management of preeclampsia/eclampsia.

(iv) Manual removal of placenta (v) removal of retained products (e.g. manual vacuum extraction, dilatation, and curettage), (vi) performing assisted vaginal delivery and (vii) performing basic neonatal resuscitation [13].

The LDHF/m-mentoring approach uses in-service learning updates to deliver information based on local needs during short, structured, onsite, interactive learning activities that involve the entire team and are spaced over time to optimize learning. It also involves 
brief, ongoing activities (e.g., skills practice, team drills, games, and quality improvement activities) at the work place to sustain learning and support clinical decision-making [11].

The training was conducted for an initial four days with emphasis on normal uncomplicated cases. After 1 month this was repeated for another four days to emphasize more complicated skills (Fig. 1). The training techniques were modified to shift the emphasis from knowledge to practice. This was a competency-based training approach that has been used in Jhpiego's (affiliate of Johns Hopkins University) training with the aim of improving and retaining the skills of the health worker. The trainer practices the skills while the trainee observes. The trainee then practices using the anatomical models (manikins) while the trainer observes. At the end, the trainer debriefs and provides feedback to the trainee.

The simulation-based clinical practice creates opportunity to improve competence through deliberate practice on anatomical models used to mimic real clinical scenario. The trainee repeats the practice until competency is achieved. The Peer Practice Coordinators (PPCs) received technical update in LDHF/m-mentoring including the use of session plans, case scenario and anatomical models (MamaNatalie/NeoNatalie) models to conduct simulation practices. The time spent on lectures was reduced and time spent on hands-on practice was increased. During the one-month interval between training courses, health care workers had opportunity to practice what they learned through high-frequency simulation-based peer practice and reinforce their competencies through high-frequency simulationbased practices of 2-3 times weekly. The PPCs completed the practice $\log$.

\section{Mobile mentoring}

The approach also uses mobile phone mentorship calls and reminder text messages to the trainees to reinforce gains made from training and resolve emerging issues at the workplaces. All the trained health workers in the $\mathrm{LDHF} / \mathrm{m}$-mentoring arm participated in mobile Mentoring (m-mentoring), which consisted of receiving weekly reminder messages and quiz questions on the topics reviewed via SMS messaging. Also the PPCs received structured, monthly half-hour mentoring calls from a trainer/master mentor that provided remote support, answering questions, providing guidance and reinforcing key messages.

\section{Measurement}

The participants undertook a pre-training assessment consisting of multiple choice questions (MCQs) and objective structured clinical examinations (OSCEs) to assess their baseline knowledge and skills on BEmONC. The MCQ contained a set of multiple choice questions to test trainees' knowledge. The OSCEs involved the use of checklists to evaluate trainees' demonstration of clinical skills to ensure that each step is correctly and completely carried out. These tools were adapted from previous studies and validated by the researchers and trainers $[6,7,12]$. The participants were assessed at three different times after training by clinicians whose clinical skills have been standardized (Fig. 1). The skills and knowledge of the participants were assessed immediately after training and at three and 12 months using MCQs and OSCEs. The assessments tested their knowledge and skills on conduct of normal delivery, active management of the third stage of labor (AMTSL), neonatal resuscitation, case management of pre-eclampsia and eclampsia (PEE) and management of PPH (e.g. manual removal of placenta, internal bimanual uterine compression and compression of the abdominal aorta). The

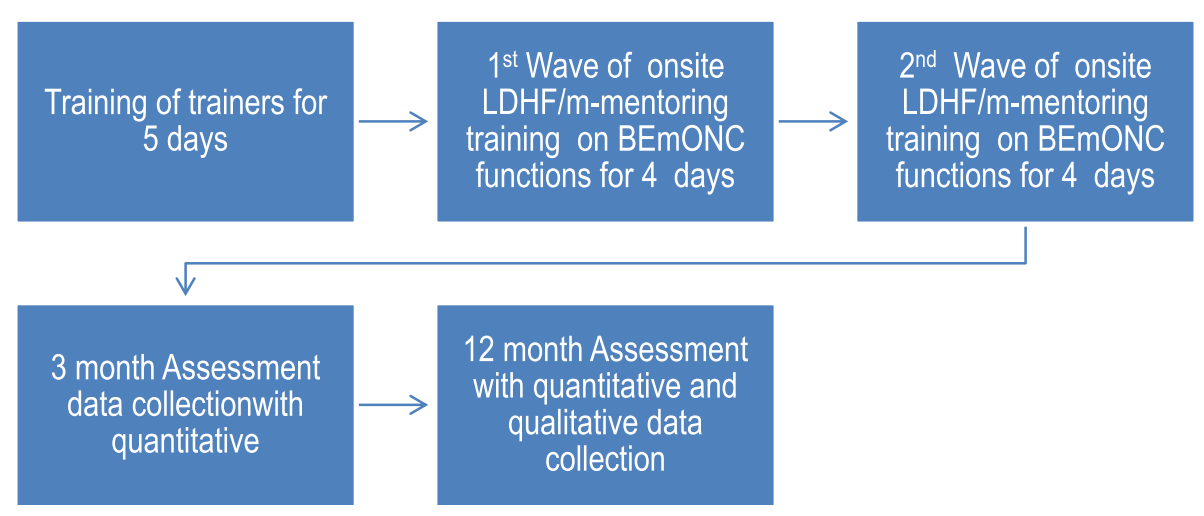

Fig. 1 Training approach 1 and data collection: Simulation based LDHF/m-mentoring training of participants - group 1 or intervention group $(\mathrm{n} 1=172)$ 
questions answered correctly and procedure done competently was scored over a total of $100 \%$. A test score of $\geq 80 \%$ was accepted as level of competence. The pretraining and immediate post-training assessments results were compared. Trainees' satisfaction with the simulation-based LDHF/m-mentoring training approach was determined using satisfaction (quantitative) survey. The scores at each assessment were collected using validated tools and recorded in real-time on android devices and sent to a central server after verification.

\section{Qualitative data}

Qualitative data were collected through six focus group discussions (FGD) comprising 8-10 participants per group purposively selected from LDHF $+\mathrm{m}$-mentoring arm at 12 months. The participants were invited via telephone and provided with the study information including its aims and procedures. All the participants gave consent. The FGDs were used to collect data on experiences and satisfaction of trainees with the LDHF/mmentoring training approach. The enquiry was based on the high-frequency practice sessions with simulators, mobile mentoring through short messages and quizzes, overall impressions of the $\mathrm{LDHF} / \mathrm{m}$-mentoring approach, and how it could be improved. In-depth interviews (IDIs) were conducted with PPCs to collect data on their experience managing simulator practice sessions, interactions with trainers/master mentors, $\mathrm{m}$ mentoring, changes made in clinical practice after the training, success, challenges and their overall impression about LDHF/m-mentoring training approach. With regard to trainers, data were collected about their experiences with the LDHF/m-mentoring training approach, successes and challenges with mobile mentoring to support the PPCs, and the effectiveness of approach in building the capacity of the health workers. The data were collected at the participants' workplaces. Only the interviewer and the respondents were present at a private place where the interviews were conducted. Interview guides were adapted from previous work and pretested. Repeated interviews were not carried out. Audio-recorders were used during interviews to help during recall. Each interview lasted for 45-60 min. The qualitative data was collected until data saturation was reached. The interviews were transcribed and data analyzed. The Transcripts were not returned to participants for comments.

Training approach 2 and data collection: traditional group training of participants (TRAD arm) - group 2 or control group

\section{Consent}

Oral consent was obtained from the study participants prior to training and assessment (measurement).

\section{Training of group 2 (TRAD) arm}

The traditional training approach consisted of eight straight days of lectures with practice sessions on simulators, outside the participants' workplace, usually in a hotel (Fig. 2). The group had lectures and practice sessions on conduct of normal delivery, AMTSL, neonatal resuscitation, case management of $\mathrm{PEE}$ and management of PPH. The BEmONC package and clinical observation checklists were used during the training sessions as was done for the intervention arm. Emphasis was not made on practice sessions at the health facilities when they returned. They did not participate in $\mathrm{m}$-Mentoring.

\section{Measurement}

Participants undertook a pre-training assessment consisting of MCQs and OSCEs to assess their baseline knowledge and skills on BEmONC. The MCQs and OSCEs were similar to those administered to the intervention group. At the end of the eight-day training, the participants had an immediate post-training assessment which included MCQs and OSCEs. As described for the intervention arm, the questions answered correctly and procedure done competently were scored out of a total of $100 \%$. These were recorded in real-time on android devices and sent to a central server after verification. The assessments results were compared. Trainees' satisfaction survey was also conducted. The participants were then assessed at different points after training. The participants were also assessed at three different times after training by clinicians whose clinical skills have been standardized.

The skills and knowledge of the participants were assessed immediately after training and at three and 12 months using MCQs and OSCEs. The assessments tested their knowledge and skills on conduct of normal delivery, AMTSL, neonatal resuscitation, case management of PEE and management of PPH (e.g. manual removal of placenta, internal bimanual uterine compression and compression of the abdominal aorta). The questions answered correctly and procedure done competently was scored over a total of $100 \%$. A test score of $\geq 80 \%$ was accepted as level of competence. The pre-training and immediate post-training assessments results were compared.

Participants in both study arms were trained and assessed by senior clinicians (mainly obstetricians, pediatricians and midwives) whose knowledge and skills were standardized. The assessment tools were pre-tested among 25 health workers from health facilities that were not part of the study. The assessment checklists for clinical skills were modified from the versions used in Ghana LDHF study [7] and piloted in accordance with the Nigeria context by the research team and data collectors. At the time of the training, MCSP did not 


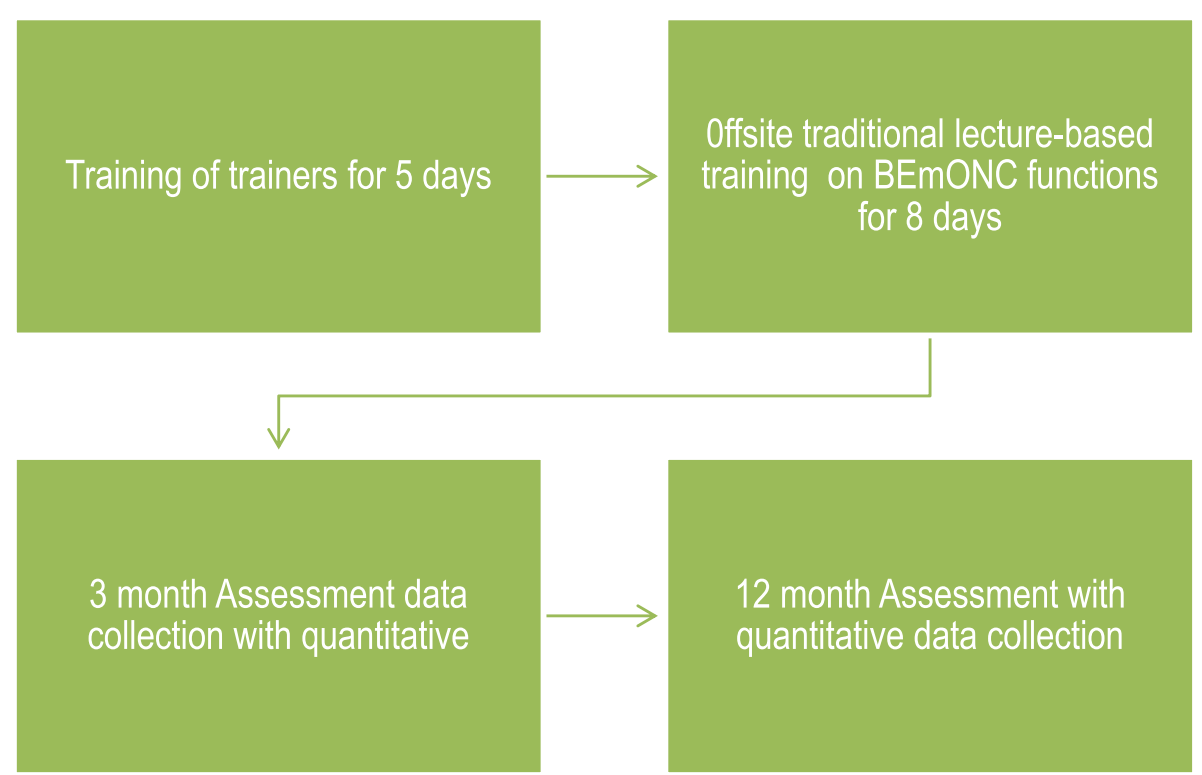

Fig. 2 Training approach 2 and data collection: Traditional off-site training of participants - group 2 or control group $(n 2=127)$

support any interventions in these facilities that are likely to cause contamination. Other quality improvement interventions only happened at the non-study facilities at the time of the study.

The assessors were blinded to the groups the participants were assigned to as they conducted the assessments.

\section{Eligibility criteria}

The sixty health facilities were selected from a sampling frame of the $120 \mathrm{MCSP}$-supported health facilities in the two states. These health facilities represented all three levels of the healthcare system in Nigeria (Primary health care or PHC, secondary, tertiary). The health workers were drawn from among those working in labor and delivery sections of the participating health facilities in the two states. In addition, the health workers had spent at least six months in the health facility providing maternal and newborn care.

\section{Randomization}

The unit of randomization in this study was the health facility. The 60 facilities were matched based on locations and level in the health care system, then divided into nine strata taking into consideration the three geopolitical wards within the states. Thereafter, each stratum was randomized to either intervention or control arm using randomly permuted blocks in a ratio of 1 : 1 so as to achieve balance in geographical location and types of health facilities in the two study arms. Those assessing outcomes were blinded to the training methodology used for the health facilities. Since there were at times less than three skilled birth attendants in some health facilities, all health workers employed in the maternity or newborn units in such facilities who met the inclusion criteria were selected from the randomized health care facilities [11].

\section{Sample size}

The details on the computation of the sample size, including the assumptions are provided in the study protocol manuscript [11]. Briefly, the required number of participants was computed as the average number of health workers to be included from each of the 60 facilities (30 per arm) using a test of two proportions. The percent of competent health workers was estimated at $50 \%$ in the control group. Study power was set at $80 \%$ to reject a null hypothesis that the proportions of competent health workers are equal in the two study arms against the alternative hypothesis of 20 percentage point difference in proportions of competent health workers between the two study arms - effect size. The significance level was set at 0.05. Sample size computation was done using PASS statistical software. The correlation of health workers competency in each health facility was assumed to be 0.05 given that some facility-level factors are shared by the health workers working together might influence how they perform certain tasks. We assumed there are about four health workers selected per facility, thus 240 health workers sampled across the two 
groups. An adjusted sample size of 300 participants (150 per study arm) was arrived at after factoring in potential 20\% drop-out during follow up period after baseline. More health workers were recruited from Kogi State since it had a larger population than Ebonyi. Study participants recruited from each facility included the maternity unit head, wherever possible, and two others to ensure that the other team members received the necessary support to practice.

\section{Data analysis}

For both arms, composite scores were computed for the infection prevention and the BEmONC functions, namely; skills in conducting normal delivery, AMTSL, neonatal resuscitation, case management of PEE with magnesium sulphate (MgSO4), and the management of primary PPH Percent scores were computed per participant based on either questions answered correctly or procedures done competently depending on the assessment tool used.

To describe categorical variables, counts and simple proportions were used. Mean and standard deviations as well as median and interquartile range were used to summarize data on continuous variables. Percentage of those achieving the required competency level of $\geq 80 \%$ post-training scores in MCQs and OSCEs were computed and compared across the two study arms. A generalized linear model was used to test the differences between arms on MCQ and OSCE scores at 12 months using a group indicator as the main predictor in the model. Furthermore, adjustments were made to account for facility-level and health worker characteristics that might have influenced the two study arms at baseline and could be strongly correlated with the outcome scores. A significance level of $<0.05$ was set for statistical significance. A longitudinal model that accounts for intra-provider correlations over time as well as within-facility correlations was developed. This model assessed the change in scores over time post-training. The model is appropriate, since it estimated using generalized estimating equations with working exchangeable correlation structure.

Regarding qualitative data, the translated Microsoft Word versions of the transcripts were imported into ATLAS.ti software (version 8.0) for content analysis. The codebook was developed by two (2) qualitative researchers, the data analyst and a second coder, using a priori codes developed from the research aims and questions, and the interview guides. In order to enhance validity, the researchers adopted a 1st tier triangulation (of researchers) and ensured a welldocumented audit trail of materials and processes. To ensure reliability, constant data comparison and comprehensive data use were done. Reliability checks were performed by each coder independently and by recoding documents already coded by the other.

\section{Results}

Two hundred and ninety-nine (299) participants completed the study out of the original 323 providers who were randomized to different study arms; LDHF/m-mentoring $\quad$ arm $=172 ; \quad$ TRAD $\quad$ arm $=127$ (Table 1 and Fig. 3). Both arms had similar sociodemographic characteristics Table 1).

Table 2 shows that the TRAD arm had better knowledge test scores compared to the LDHF/mmentoring arm at baseline and immediately after the training intervention in some thematic areas, such as AMTSL and neonatal resuscitation $(p<0.05)$. However, at 3 and 12 months after training assessment, both arms were equal in knowledge acquisition and retention; no statistically significant differences were evident.

Health workers in both arms showed improvement in overall pass rates in clinical skills competency, improving from around $30 \%$ at baseline to $75 \%$ and above at endline; difference-in-differences were statistically significant $(p<0.05)$; TRAD (from 27.4 to $74.8 \%$ ) and LDHF/m-mentoring (from 30.1 to 81.1\%). Overall, the observed improvement and retention of BEmONC skills was higher in $\mathrm{LDHF} / \mathrm{m}$ mentoring study arm participants (81.1\%) compared to the TRAD arm participants $(74.8 \%)$ at 12 months post-training $(p<0.05)$. There was a slight drop in skills competency in both arms at the three-month assessment (Fig. 4).

Figure 5 shows that overall for BEmONC skills, the LDHF/m-mentoring arms had better post-training assessment scores at 12 months post-training for assisting normal birth (including care of the newborn), AMTSL, manual removal of placenta, bimanual compression of the uterus, abdominal aortic compression, PEE management $(p<0.05)$.

Analysis codes were grouped into four thematic categories, guided by both the specific objectives, research questions and those that emerged from the data.

The results of the qualitative study are presented in four sections. The first section addressed knowledge and skill learning outcomes of birth attendants following simulation-based LDHF/m-mentoring, the second section addressed trainees' satisfaction with successful outcomes following simulation-based LDHF/m-mentoring approach, third section addressed facilitators of LDHF/m-Mentoring approach and the fourth section addressed the barriers to $\mathrm{LDHF} / \mathrm{m}$ mentoring approach. 
Table 1 Baseline characteristics of study sample of providers by study arm, $N=299$

\begin{tabular}{|c|c|c|c|}
\hline Characteristic of Health Workers & $\begin{array}{l}\text { LDHF/m-mentoring ( } 1=172) \\
\mathrm{n}(\%)\end{array}$ & $\begin{array}{l}\text { TRAD (n2 = 127) } \\
\mathrm{n}(\%)\end{array}$ & $p$ value \\
\hline \multicolumn{4}{|l|}{ State or Location } \\
\hline Ebonyi & $63(36.6)$ & $33(26.011)$ & \multirow[t]{2}{*}{$0.05^{\mathrm{a}}$} \\
\hline Kogi & $109(63.4)$ & $94(74.0)$ & \\
\hline \multicolumn{4}{|l|}{ Type of Facility } \\
\hline Primary health center & $66(38.4)$ & $60(47.2)$ & \\
\hline General/Mission hospital & $90(52.3)$ & 49 (38.6) & \\
\hline Tertiary hospital & $16(9.3)$ & $18(14.2)$ & $0.05^{\mathrm{a}}$ \\
\hline Mean (SD) Age: years & $41.0(10.3)$ & $40.6(8.8)$ & $0.78^{\mathrm{b}}$ \\
\hline \multicolumn{4}{|l|}{ Sex } \\
\hline Male & $27(15.7)$ & $28(22.0)$ & \multirow[t]{2}{*}{$0.16^{\mathrm{a}}$} \\
\hline Female & $145(84.3)$ & $99(78.0)$ & \\
\hline \multicolumn{4}{|l|}{ Marital Status } \\
\hline Married & $145(84.3)$ & $113(89.0)$ & \multirow[t]{4}{*}{$0.60^{c}$} \\
\hline Single & $18(10.4)$ & $11(8.6)$ & \\
\hline Divorced & $1(0.6)$ & $0(0.0)$ & \\
\hline Widowed & $8(4.7)$ & $3(2.4)$ & \\
\hline \multicolumn{4}{|l|}{ Religion } \\
\hline Christian & $137(79.7)$ & $95(74.8)$ & \multirow[t]{4}{*}{$0.33^{\mathrm{a}}$} \\
\hline Islam & $32(18.6)$ & $29(22.8)$ & \\
\hline Other & $0(0.0)$ & $1(0.8)$ & \\
\hline Missing & $3(1.7)$ & $2(1.6)$ & \\
\hline Duration Since Graduation: years & $12.0(6.0-23.0)$ & $14.0(8.0-21.0)$ & $0.54^{d}$ \\
\hline \multicolumn{4}{|l|}{ Cadre/Job Title } \\
\hline Community health extension worker & $59(34.3)$ & $55(43.3)$ & \multirow[t]{4}{*}{$0.03^{* c}$} \\
\hline Doctor & $6(3.5)$ & $11(8.7)$ & \\
\hline Nurse & $98(57.0)$ & $59(46.4)$ & \\
\hline Other & $9(5.2)$ & $2(1.6)$ & \\
\hline Median (IQR) Duration Working at Facility since Employment: years & $6.0(3.0-10.0)$ & $6.0(3.0-10.0)$ & $0.84^{\mathrm{d}}$ \\
\hline Median (IQR) of travel time to training (minutes) ${ }^{\mathrm{e}}$ & $60.0(60.0-90.0)$ & $60.0(60.0-120.0)$ & $<0.001^{* d}$ \\
\hline Duration at current position: median (IQR) in years & $8.0(4.0-18.0)$ & $9.0(4.0-15.0)$ & $0.76^{\mathrm{d}}$ \\
\hline
\end{tabular}

Types of tests: ${ }^{a}=$ Pearson's chi-squared; ${ }^{b}=$ Two sample t test; $^{c}=$ Fisher's exact; $^{d}=$ Wilcoxon rank-sum. SD, standard deviation; IQR, interquartile range. ${ }^{*},=$ statistical significance ${ }^{\mathrm{e}}=$ TRAD participants residing within $5 \mathrm{~km}$ of the training sites were not accommodated in a hotel; they travelled daily to the training site

Excerpts from respondents are presented in italics. Each quote in the text is labeled by type of interview and State.

Theme 1: Knowledge and skill learning outcomes of birth attendants

In both states, all the FDG participants opined that the LDHF/m-mentoring training approach enabled them gain improvement in skills/knowledge and quality of care.

An FGD participant in Ebonyi said:

'The training was different to me by emphasizing that the partograph is a medico-legal document.

The training endeared me to the use of partograph to monitor labour and the importance of documentation. We have started using partograph. Before now, we were not using partograph to manage labour' (FGD, Ebonyi).

Theme 2: Trainees' satisfaction with successful outcomes following the simulation-based LDHF/m-mentoring approach

The respondents reported reduction in maternal and neonatal morbidity and mortality as common theme across states.

We have saved babies that would have died. Now babies can be resuscitated so more babies are surviving and we are having more successful deliveries. 


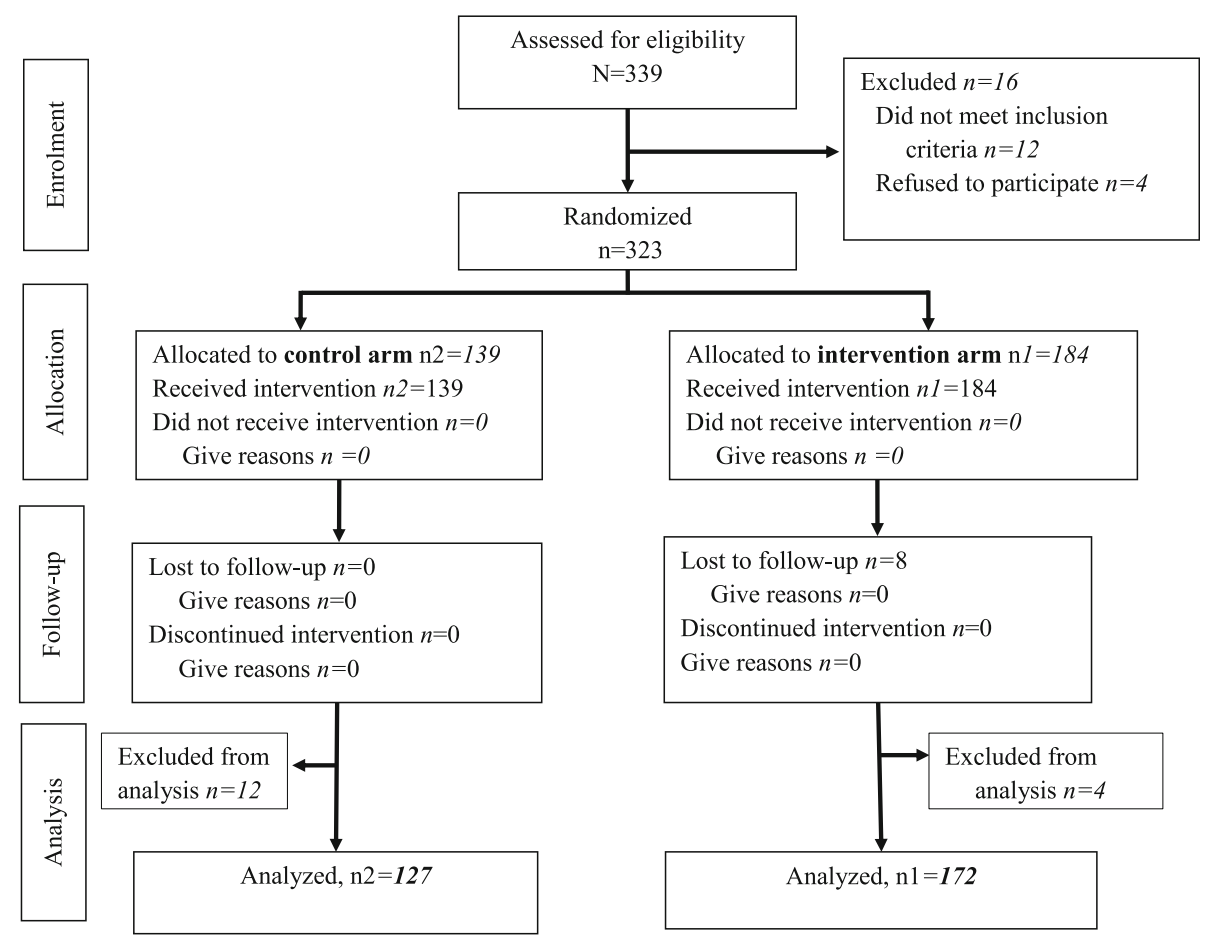

Fig. 3 Consort flowchart of enrolment of study participants and data analysis

Theme 3: Facilitators of LDHF/m-mentoring approach Respondents identified facilitators of LDHF/m-Mentoring approach as support provided by the implementing partners through availability of equipment/supplies, use of telephone for communication, expert knowledge/skill and support from master mentors, incentives/welfare such as transport reimbursement and meals during training, support from management of facilities such as arrangement of duty rosters to enable trainees attend practices sessions and assessments through text messages and quizzes.

A respondent in Ebonyi state said:

'Our implementing partners are the biggest supporter of this program, they trained us.'

\section{Theme 4: barriers to LDHF/m-mentoring approach}

The barriers mentioned included that different work schedules prevented some trainees from attending some practice sessions and unavailability of equipment hindered some from translating what they learnt into practice.

'I find it difficult bringing everybody together at the same time because we run different shifts. It was very difficult to get members of the group to come together and practice due to our work schedules' (IDI, Ebonyi).

\section{Discussion}

In this cluster randomized control trial, the knowledge assessment scores increased from baseline to end-line in both the study arms. The acquisition and retention of BEmONC skills differed at 12 months with the LDHF/ m-mentoring arm demonstrating better performance than the TRAD arm. This study contributes to the much needed evidence base for $\mathrm{LDHF} / \mathrm{m}$-mentoring training approach in Low -and Middle- Income Countries (LMICs), adding on the finding of related studies done in Ghana [7] and Uganda [8]. As part of the intervention package, LDHF/m-mentoring study arm participants received weekly SMS reminders and quizzes along with continuous skills practice on anatomical models, which helped, reinforce knowledge on specific clinical areas over time. In contrast, the TRAD arm participants, which represented the status-quo, did not have the extra support, which might explain the differences in skills performance at 12 months. Furthermore, information gathered qualitatively suggests that a key benefit of $\mathrm{m}$ mentoring is the ability of trainees to call their mentors at the point of care to address complications such as placenta praevia or birth asphyxia. This close mentormentee relationship might also have helped the mentees to develop confidence in these clinical skills, which demonstrates a great potential of the $\mathrm{LDHF} / \mathrm{m}$-mentoring approach. 
Table 2 Comparison of levels of knowledge between study arms across four assessment periods, $N=299$

\begin{tabular}{|c|c|c|c|c|c|c|c|c|}
\hline \multirow{3}{*}{$\begin{array}{l}\text { Thematic } \\
\text { Area \# }\end{array}$} & \multirow[t]{3}{*}{ Thematic Area } & \multirow{3}{*}{$\begin{array}{l}\text { Total number of } \\
\text { items }\end{array}$} & \multicolumn{6}{|c|}{ Assessment 1-Baseline } \\
\hline & & & \multirow[b]{2}{*}{$\begin{array}{l}\text { Mean \# correct, } \\
\text { LDHF/m-mentoring }\end{array}$} & \multirow[b]{2}{*}{$\begin{array}{l}\text { Mean \# correct, } \\
\text { TRAD }\end{array}$} & \multicolumn{2}{|l|}{$\begin{array}{l}\text { Unadjusted } \\
\text { analysis }\end{array}$} & \multicolumn{2}{|c|}{ Adjusted analysis } \\
\hline & & & & & IRR $(95 \% \mathrm{Cl})$ & $p$ value & IRR $(95 \% \mathrm{Cl})$ & $p$ value \\
\hline 1 & $\begin{array}{l}\text { Infection } \\
\text { prevention }\end{array}$ & 6 & 3.17 & 2.67 & $1.19(1.07,1.32)$ & $0.001^{*}$ & $1.17(1.06,1.30)$ & $0.002^{*}$ \\
\hline 2 & Normal birth & 8 & 4.17 & 4.01 & $1.04(0.96,1.13)$ & 0.349 & $1.03(0.95,1.12)$ & 0.498 \\
\hline 3 & AMTSL & 4 & 1.79 & 1.73 & $1.03(0.88,1.21)$ & 0.682 & $1.02(0.88,1.18)$ & 0.822 \\
\hline 4 & $\begin{array}{l}\text { Management of } \\
\text { eclampsia }\end{array}$ & 2 & 1.13 & 1.11 & $1.02(0.89,1.18)$ & 0.754 & $1.02(0.88,1.17)$ & 0.805 \\
\hline 5 & $\begin{array}{l}\text { Essential newborn } \\
\text { care }\end{array}$ & 2 & 0.94 & 1.03 & $.92(0.77,1.09)$ & 0.318 & $0.91(0.76,1.08)$ & 0.270 \\
\hline \multirow[t]{2}{*}{6} & $\begin{array}{l}\text { Neonatal } \\
\text { resuscitation }\end{array}$ & 20 & 8.55 & 11.15 & $0.77(0.70,0.84)$ & $<0.001^{*}$ & $0.75(0.68,0.82)$ & $<0.001^{\circ}$ \\
\hline & Overall score & 42 & 17.62 & 19.71 & $0.89(0.83,0.96)$ & $0.002^{*}$ & $0.88(0.82,0.94)$ & $<0.001^{\prime}$ \\
\hline \multirow[t]{3}{*}{$\begin{array}{l}\text { Thematic } \\
\text { Area \# }\end{array}$} & & $\begin{array}{l}\text { Total number } \\
\text { of items }\end{array}$ & \multicolumn{6}{|c|}{$\begin{array}{l}\text { Assessment 2-Immediate } \\
\text { post-training }\end{array}$} \\
\hline & & & & & \multicolumn{2}{|l|}{$\begin{array}{l}\text { Unadjusted } \\
\text { analysis }\end{array}$} & \multicolumn{2}{|c|}{ Adjusted analysis } \\
\hline & Thematic Area & & $\begin{array}{l}\text { Mean \# correct, } \\
\text { LDHF/m-mentoring }\end{array}$ & Mean \# correct, TRAD & IRR $(95 \% \mathrm{Cl})$ & $p$ value & IRR $(95 \% \mathrm{Cl})$ & $p$ value \\
\hline 1 & $\begin{array}{l}\text { Infection } \\
\text { prevention }\end{array}$ & 6 & 5.01 & 5.04 & $1.00(0.94,1.06)$ & 0.888 & $0.98(0.92,1.04)$ & 0.470 \\
\hline 2 & Normal birth & 8 & 6.51 & 6.76 & $0.96(0.92,1.01)$ & 0.134 & $0.95(0.90,1.00)$ & $0.040^{*}$ \\
\hline 3 & AMTSL & 4 & 3.2 & 3.49 & $.92(0.86,0.98)$ & $0.009^{*}$ & $0.90(0.84,0.96)$ & $0.002^{*}$ \\
\hline 4 & Management of eclampsia & 2 & 1.72 & 1.8 & $0.95(0.89,1.02)$ & 0.138 & $0.95(0.89,1.01)$ & 0.116 \\
\hline 5 & $\begin{array}{l}\text { Essential newborn } \\
\text { care }\end{array}$ & 2 & 1.34 & 1.65 & $0.81(0.74,0.89)$ & $<0.001^{*}$ & $0.80(0.72,0.88)$ & $<0.001^{*}$ \\
\hline \multirow[t]{2}{*}{6} & $\begin{array}{l}\text { Neonatal } \\
\text { resuscitation }\end{array}$ & 20 & 11.29 & 16.21 & $0.7(0.63,0.77)$ & $<0.001^{*}$ & $0.68(0.61,0.75)$ & $<0.001$ \\
\hline & Overall score & 42 & 24.21 & 30.57 & $0.79(0.75,0.84)$ & $<0.001^{*}$ & $0.77(0.73,0.82)$ & $<0.001^{\circ}$ \\
\hline \multirow{3}{*}{$\begin{array}{l}\text { Thematic } \\
\text { Area \# }\end{array}$} & & $\begin{array}{l}\text { Total number } \\
\text { of items }\end{array}$ & \multirow{2}{*}{\multicolumn{2}{|c|}{ Assessment $3-3$ months post-training }} & & & & \\
\hline & & & & & \multicolumn{2}{|c|}{ Unadjusted analysis } & \multicolumn{2}{|c|}{ Adjusted analysis } \\
\hline & Thematic Area & & $\begin{array}{l}\text { Mean \# correct, } \\
\text { LDHF/m-mentoring }\end{array}$ & $\begin{array}{l}\text { Mean \# correct, } \\
\text { TRAD }\end{array}$ & $\begin{array}{l}\text { IRR } \\
(95 \% \mathrm{Cl})\end{array}$ & $p$ value & $\begin{array}{l}\text { IRR } \\
(95 \% \mathrm{Cl})\end{array}$ & $p$ value \\
\hline 1 & $\begin{array}{l}\text { Infection } \\
\text { prevention }\end{array}$ & 6 & 4.54 & 4.24 & $1.07(0.99,1.16)$ & 0.086 & $1.04(0.96,1.12)$ & 0.348 \\
\hline 2 & Normal Birth & 8 & 5.9 & 5.7 & $1.04(0.96,1.11)$ & 0.342 & $1.01(0.94,1.08)$ & 0.760 \\
\hline 3 & AMTSL & 4 & 3.07 & 3.04 & $1.01(0.92,1.10)$ & 0.853 & $0.97(0.89,1.06)$ & 0.569 \\
\hline 4 & $\begin{array}{l}\text { Management } \\
\text { of Eclampsia }\end{array}$ & 2 & 1.69 & 1.7 & $1.00(0.92,1.08)$ & 0.932 & $0.99(0.91,1.07)$ & 0.741 \\
\hline 5 & $\begin{array}{l}\text { Essential Newborn } \\
\text { Care }\end{array}$ & 2 & 1.55 & 1.52 & $1.02(0.91,1.14)$ & 0.781 & $1.00(0.89,1.12)$ & 0.964 \\
\hline \multirow[t]{2}{*}{6} & $\begin{array}{l}\text { Neonatal } \\
\text { Resuscitation }\end{array}$ & 20 & 14.45 & 13.98 & $1.03(0.96,1.11)$ & 0.372 & $1.00(0.93,1.08)$ & 0.978 \\
\hline & Overall score & 42 & 27.41 & 26.37 & $1.04(0.98,1.10)$ & 0.200 & $1.01(0.95,1.06)$ & 0.796 \\
\hline \multirow[t]{2}{*}{$\begin{array}{l}\text { Thematic } \\
\text { Area \# }\end{array}$} & & $\begin{array}{l}\text { Total number } \\
\text { of items }\end{array}$ & \multicolumn{2}{|c|}{ Assessment $4-12$ months post-training } & \multicolumn{2}{|c|}{ Unadjusted analysis } & \multicolumn{2}{|c|}{ Adjusted analysis } \\
\hline & Thematic Area & & $\begin{array}{l}\text { Mean \# correct, } \\
\text { LDHF/m-mentoring }\end{array}$ & $\begin{array}{l}\text { Mean \# correct, } \\
\text { TRAD }\end{array}$ & $\begin{array}{l}\text { IRR } \\
(95 \% \mathrm{Cl})\end{array}$ & $p$ value & $\begin{array}{l}\text { IRR } \\
(95 \% \mathrm{Cl})\end{array}$ & $p$ value \\
\hline 1 & $\begin{array}{l}\text { Infection } \\
\text { prevention }\end{array}$ & 6 & 4.15 & 3.99 & $1.04(0.95,1.14)$ & 0.380 & $1.01(0.93,1.10)$ & 0.795 \\
\hline 2 & Normal birth & 8 & 5.59 & 5.32 & $1.05(0.97,1.14)$ & 0.213 & $1.03(.95,1.11)$ & 0.470 \\
\hline 3 & AMTSL & 4 & 2.88 & 2.89 & $1.00(0.90,1.10)$ & 0.944 & $0.96(0.88,1.06)$ & 0.426 \\
\hline 4 & Management & 2 & 1.61 & 1.59 & $1.02(0.93,1.11)$ & 0.730 & $1.00(0.92,1.10)$ & 0.920 \\
\hline
\end{tabular}


Table 2 Comparison of levels of knowledge between study arms across four assessment periods, $N=299$ (Continued)

\begin{tabular}{|c|c|c|c|c|c|c|c|c|}
\hline & of eclampsia & & & & & & & \\
\hline 5 & $\begin{array}{l}\text { Essential newborn } \\
\text { care }\end{array}$ & 2 & 1.51 & 1.46 & $1.04(0.93,1.16)$ & 0.544 & $1.01(0.90,1.13)$ & 0.867 \\
\hline \multirow[t]{2}{*}{6} & $\begin{array}{l}\text { Neonatal } \\
\text { resuscitation }\end{array}$ & 20 & 13.83 & 14.02 & $0.99(0.94,1.04)$ & 0.588 & $0.95(0.91,1.00)$ & $0.036^{*}$ \\
\hline & Overall score & 42 & 26.47 & 26.16 & $1.01(0.96,1.06)$ & 0.642 & $0.98(0.94,1.02)$ & 0.340 \\
\hline
\end{tabular}

*indicates statistical significance or $p<0.05$

IRR incidence rate ratio, $\mathrm{Cl}$ Confidence interval

Overall, the LDHF/m-mentoring arm had better skills performance at all the assessment points compared to the TRAD arm. The qualitative data also support this improvement in knowledge and skills related to maternal and newborn care and outcomes.

There was an observed drop in skills competency at three months in both arms from the immediate posttraining assessment. Some of the possible explanation for the drop in skills competency is that it took time following intense training, before a practice was established as routine. Another possible cause for the drop was a health workers' strike that was occurred just before the post-training assessments in the two states. Despite these factors, the LDHF/m-mentoring arm still performed better in all competencies at three and 12months post-training. It is encouraging to note that this observed better performance was in competences that were very crucial for the survival of the mother and the baby on the day of birth; these include, AMTSL, manual removal of placenta, neonatal resuscitation, loading dose of $\mathrm{MgSO} 4$, and pre-eclampsia/eclampsia. The continued simulation practice may have helped in building and retaining these competencies.
Studies on BEmONC in-service training have demonstrated the value of simulation and continuous practice in improving knowledge and skills competency $[7,8]$. This has led to adaptation of various approaches to determine which ones led to the greatest returns on investment $[1-4,7,9-11]$. Our findings are consistent with those of previous studies that reported that TRAD offsite training may improve the trainees' competencies, but knowledge and skills may not be readily transferred to other co-workers at the facility, nor translated into practice or performance $[13,14]$. On the other hand, methods that involve repetitive, mentor-supported learning and regularly coordinated practice sessions, such as the onsite LDHF/ $\mathrm{m}$-mentoring training, resulted in better skills acquisition and retention over time $[1,2,5,7,8,15-17]$. This claim has been supported by other well-designed studies that showed that onsite LDHF/m-mentoring training approach, coupled with an efficient mentorship program, resulted in improved provider preparedness to deal with complications $[7,8,16]$.

Findings from another study that measured patientlevel outcomes showed that the LDHF/m-mentoring

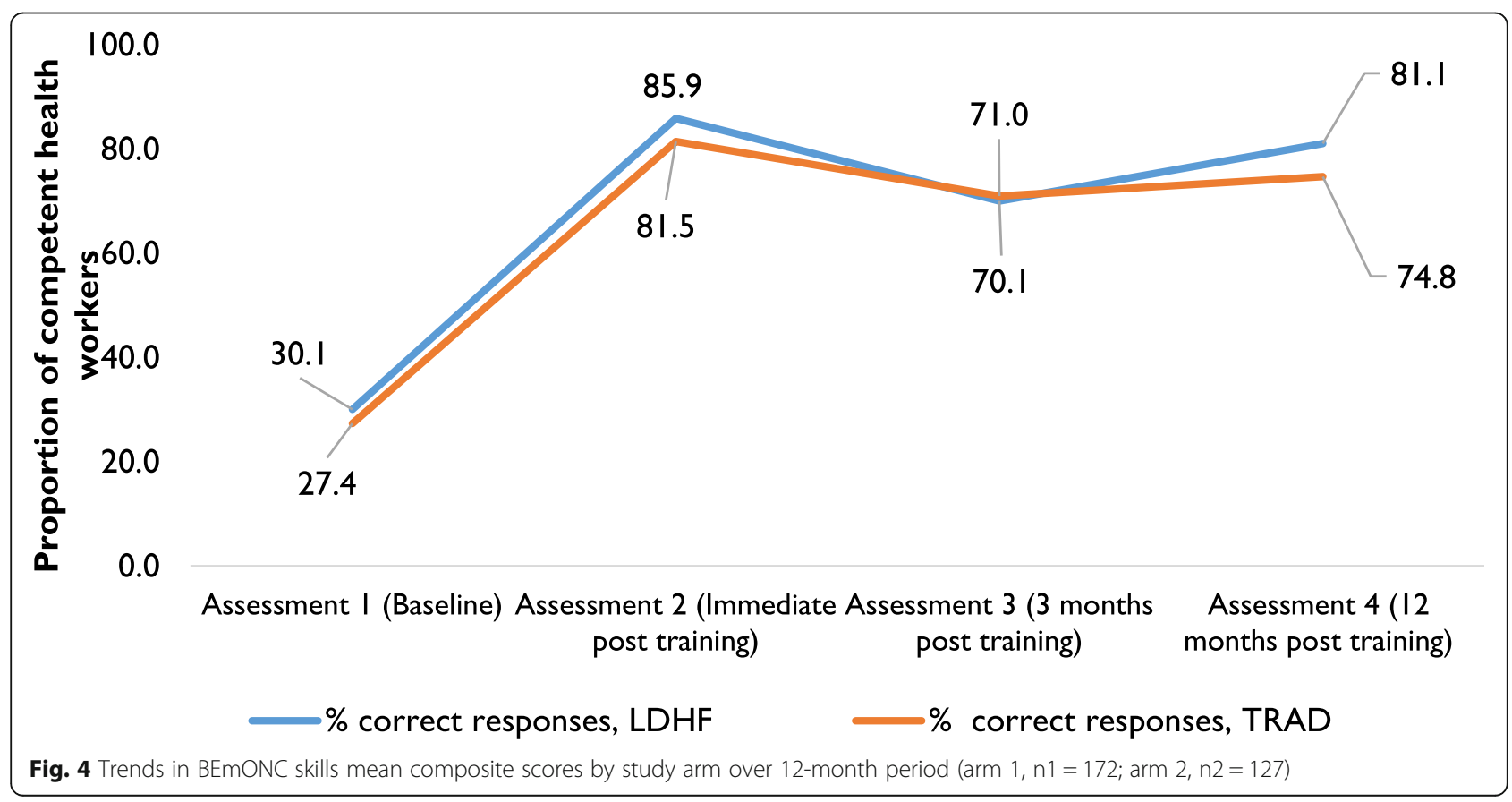




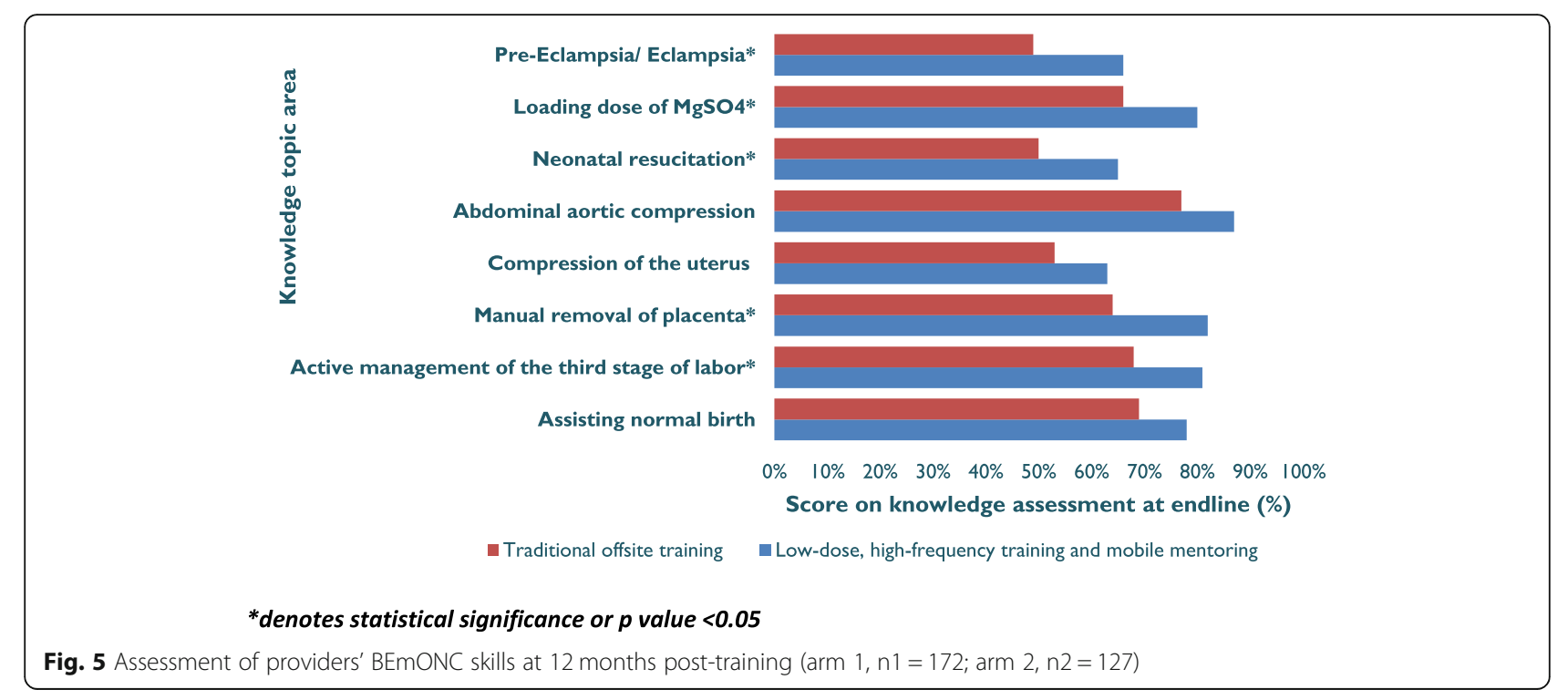

training approach was associated with a sustained decrease in facility-based newborn mortality and intrapartum stillbirths in Ghana [7]. The limitations acknowledged by the authors, such as the lack of a randomized control trial design and lack of concealment/information bias, have been addressed in our study using a cluster randomized controlled trial in a similar lowresource setting. Although our study did not objectively measure patient-level outcomes other than health workers report of reduced morbidities and mortalities during the qualitative study, we assessed a crucial component of the day of birth, namely the competency of the service providers. Our study was adequately powered to produce generalizable conclusions on the comparative effectiveness of the LDHF/m-mentoring and TRAD approaches in the study setting and possibly in similar environments especially in LMICs. As reported by other studies, to be effective, training programs should be conducted as close as possible to the workplace and be competency-based $[5,17,18]$.

The present study also adds to the growing yet still insufficient body of evidence in LMICs supporting the use of simulation, specifically for training in the management of obstetrics and newborn emergencies [19-21]. Skills that are not used very frequently in management of obstetric and newborn complications are likely to be non-existent or lost due to a lack of use, and therefore the need to practice often. The appropriate dose or frequency of practice in order to reach competency level depends on many factors, which include the personal attributes of health worker among other things. Simulation-based trainings provide participants with the opportunity to repeat practice sessions in a safe environment where they will not harm patients $[7,8,18,21]$. Using the workplace to practice skills is beneficial. The availability of the anatomical models for continuous onsite simulation practice sessions also helps to organize emergency drills to test the health systems response to life-threatening complications.

Another important finding is that some of the facilitators for the LDHF/m-mentoring approach are related to successful outcomes that were reported as health workers improved their skills, which motivated the participants to practice more and seek support from master mentors. Inadequate mentorship should be addressed to improve quality of BEmONC [22]. On the other hand, some of the barriers to this approach included lack of medical equipment and supplies, strikes by health workers, different work schedules and workplace distraction also limited peer practice sessions. To function maximally, health workers need to improve their competency and they need an enabling environment, including availability of supplies, equipment, appropriate guidelines and policies, and timely remuneration [23, 24]. Our study findings corroborated those of previous studies in LMICs on the effectiveness of the LDHF/m-mentoring training approach compared to the offsite traditional training approach to build health workers capacity $[7,8]$.

This study had some limitations. These include some operational-level logistic challenges in ensuring that the mentors always had the airtime in a timely manner in order to maintain seamless communication with the mentees. This was mitigated by the mentors being very understanding by using their own funds to procure air time used for $\mathrm{m}$-mentoring as they awaited support provided through the study. Another limitation was the health workers' strike which occurred around three months post-training, which negatively affected the findings at that assessment period. Finally, although the study team appealed to Ministry of Health $(\mathrm{MoH})$ not to 
transfer the study participants to other non-study facilities for the duration of the study, some staff were transferred.

\section{Conclusion}

This is one of the few studies from one of the LMICs that have used a pragmatic design - a cluster randomized controlled trial and qualitative methods-to generate much needed information on learning outcomes of two approaches to health worker capacity building. Our study findings corroborated those of similar studies to support the proposition to a shift from traditional offsite group-based training to low-dose, high-frequency and onsite training as an effective way to build the capacity of maternal and newborn care providers. This shift can be explored in other clinical settings to improve the quality of care. The findings suggest that a low-dose, high frequency and simulation- and practice-based training approach, including mobile mentoring is likely to result in better skills competency outcomes and higher skills retention among health workers. This study has demonstrated promising results that can address health worker absenteeism due to frequent offsite trainings, which are a major concern for health facility managers in LMICs. Training staff onsite without taking them away from service delivery points is a strong reason for adoption of the simulation-based low dose high frequency/mobile mentoring approach.

The findings are expected to provide health facility managers and other decision makers with valuable information to guide resource allocation for maximum benefit and effectiveness in building the capacity of frontline health workers. The authors recommend that capacity building among healthcare workers, to the extent possible, should utilize the onsite $\mathrm{LDHF} / \mathrm{m}$-mentoring learning approach. Further evidence is needed to determine the value of $\mathrm{m}$-mentoring in influencing learning outcomes and the cost-effectiveness of both training approaches as these were not explored in our study.

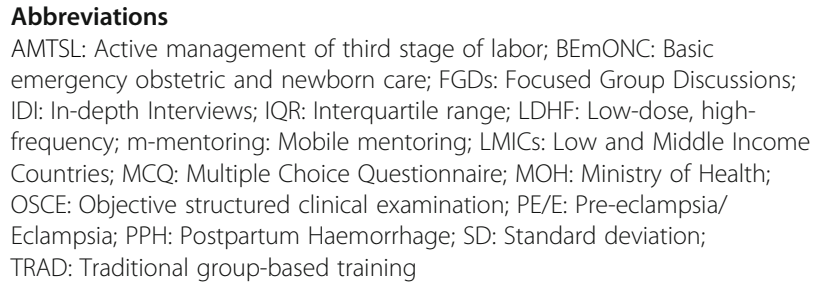

\section{Acknowledgements}

The authors acknowledge the support received from the Federal Ministry of Health, Ebonyi State Ministry of Health and Kogi State Ministry of Health, Nigeria and health workers in all the selected health facilities during the design and implementation stages. We are sincerely grateful to Dr. Iwasam Agbor and Hospiman Global Research Firm for working on the qualitative data collection, analysis and report writing. We also acknowledge and sincerely thank Elizabeth Thompson, Barbara Rawlins, Jennifer Hoeg and Emmanuel Ani for reviewing the manuscript and making very valuable corrections. Finally we are grateful to Edward Bunker who worked tirelessly to provide support in data de-identification.

\section{Authors' contributions}

EU, MK, EO, GY, AO, BO1, UO, JE, Gl, GA, GO, OA, CO, AA and BO2 contributed to the data collection, analysis and development of the manuscript. EU, MK, EO and GY conceived the idea of the manuscript and wrote the initial draft. All other authors contributed significantly to the research project and manuscript development. All authors read and approved the final manuscript.

\section{Funding}

This study was made possible by the generous support of the American people through the United States Agency for International Development (USAID) under the terms of the Cooperative Agreement AID-OAA-A-1400028. The contents are the responsibility of the authors and do not necessarily reflect the views of USAID or the United States Government. The USAID contributed to the design of the study by improving the methodology rigor and also reviewed the final manuscript.

\section{Availability of data and materials}

The datasets generated and/or analyzed during the current study are available in the figshare repository, https://doi.org/10.6084/m9.figshare. 9955133

\section{Ethics approval and consent to participate}

Ethical approval was obtained from Nigerian Health Research Ethics Committee with approval number NHREC/ 01/01/2007 November 2015 and the Johns Hopkins School of Public Health, Institutional Review Board \#000007196, on August 23rd, 2016. The trial was retrospectively registered with the NIH-Sponsored ClinicalTrials. Gov registry on 24th August, 2017: NCT03269240. Verbal informed consent was obtained from study participants and confidentiality was assured. Verbal informed consent was used because the authors thought that asking health providers to review and sign forms might be considered risky because of the fear that if they performed poorly their supervisors may see their scores and trace it back to them.

\section{Consent for publication}

Not applicable.

\section{Competing interests}

The authors declare that they have no competing interest.

\section{Author details}

'USAID's Maternal and Child Survival Program/Jhpiego, Nigeria, 971 Reuben Okoya Crescent, Wuye District, Abuja, Nigeria. ${ }^{2}$ USAID's Maternal and Child Survival Program/Jhpiego-, 1615 Thames St, Baltimore, MD 21231, USA. ${ }^{3}$ The Johns Hopkins Biostatistics Center, Johns Hopkins Bloomberg School of Public Health, 615 N. Wolfe Street, Baltimore, MD, USA. ${ }^{4}$ Department of Public Health, State Ministry of Health, Lokoja, Kogi State, Nigeria. ${ }^{5}$ Department of Public Health, State Ministry of Health, Abakiliki, Ebonyi State, Nigeria.

Received: 18 January 2020 Accepted: 19 June 2020

Published online: 26 June 2020

\section{References}

1. Nkwo PO, Lawani LO, Ubesie AC, Onodugo VA, Obu HA, Chinawa JM. Poor availability of skilled birth attendants in Nigeria: a case study of Enugu state primary health care system. Ann Med Health Sci Res. 2015;5:20-5.

2. Bluestone J, Johnson P, Fullerton J, Carr C, Alderman J, BonTempo J. Effective in-service training design and delivery: evidence from an integrated literature review. Hum Resour Health. 2013;11:51.

3. Banke-Thomas A, Wilson-Jones M, Madaj B, van den Broek N. Economic evaluation of emergency obstetric care training: a systematic review. BMC Pregnancy Childbirth. 2017. https://doi.org/10.1186/s12884-017-1586-z.

4. Frank K, Lombaard H, Pattinson R. Does completion of the essential steps in managing obstetric emergencies (ESMOE) training package result in improved knowledge and skills in managing obstetric emergencies? South Afr J Obstet. 2009;15:94-9. 
5. Ameh CA, van den Broek N. Making it happen: training health-care providers in emergency obstetric and newborn care. Best Pract Res Clin Obstet Gynaecol. 2015;29:1077-91.

6. Shoushtarian M, Barnett M, McMahon F, Ferris J. Impact of introducing practical obstetric multi-professional training (PROMPT) into maternity units in Victoria, Australia. BJOG. 2014;121:1710-8.

7. Gomez PP, Nelson AR, Asiedu A, Addo E, Agbodza D, Allen C, et al. Accelerating newborn survival in Ghana through a low-dose, highfrequency health worker training approach: a cluster randomized trial. BMC Pregnancy Childbirth. 2018. https://doi.org/10.1186/s12884-018-1705-5.

8. Evans CL, Bazant E, Atukunda I, Williams E, Niermeyer S, Hiner C, et al. Peerassisted learning after onsite, low-dose, high-frequency training and practice on simulators to prevent and treat postpartum hemorrhage and neonatal asphyxia: A pragmatic trial in 12 districts in Uganda. PLoS ONE. 2018. https://doi.org/10.1371/journal.pone.0207909.

9. Leslie HH, Gage A, Nsona H, Hirschhorn LR, Kruk ME. Training and supervision did not meaningfully improve quality of care for pregnant women or sick children in Sub-Saharan Africa. Health Aff (Millwood). 2016. https://doi.org/10.1377/hlthaff.2016.0261.

10. Gulmezoglu AM, Lawrie TA. Impact of training on emergency resuscitation skills: Impact on Millennium Development Goals (MDGs) 4 and 5. Best Pract Res Clin Obstet Gynaecol. 2015. https://doi.org/10.1016/j.bpobgyn.2015.03. 018.

11. Ugwa E, Otolorin E, Kabue M, Ishola G, Evans C, Oniyire A, et al. Simulationbased low-dose, high-frequency plus mobile mentoring versus traditional group-based training approaches on day of birth care among maternal and newborn healthcare providers in Ebonyi and Kogi states, Nigeria; a randomized controlled trial. BMC Health Serv Res. 2018;18:630.

12. Al-Elq AH. Simulation-based medical teaching and learning. J Family Community Med. 2010;17(1):35-40. https://doi.org/10.4103/1319-1683.68787.

13. Otolorin E, Gomez P, Currie S, Thapa K, Dao B. Essential basic and emergency obstetric and newborn care: from education and training to service delivery and quality of care. Int J Gynecol Obstet. 2015;130:S46-53.

14. Evans CL, Bazant E, Johnson P, Hiner C, Williams E, Conecker G, et al. Saving Lives at Birth Final Report: Building and Sustaining Capacity of Frontline Health Workers in Uganda. Baltimore: A partnership of: Jhpiego, USAID, Norwegian Ministry of Foreign Affairs; Bill \& Melinda Gates Foundation; Grand Challenges Canada; UKaid; American Academy of Pediatrics; Laerdal; 2016.

15. Evans $C L$, Johnson $P$, Bazant $E$, Bhatnagar N, Zgambo J, Khamis AR. Competency-based training Helping Mothers Survive: Bleeding after Birth for providers from central and remote facilities in three countries. Int. J. Gynecol. Obstet. 2014. https://doi.org/10.1016/j.jggo.2014.02.021.

16. Sutton RM, Niles D, Meaney P, Aplenc R, French B, Abella BS, et al. Lowdose, high-frequency CPR training improves skill retention of in-hospital pediatric providers. Pediatrics. 2011;128:e145-51.

17. Jayanna K, Bradley J, Mony P, Cunningham T, Washington M, Bhat S, et al. Effectiveness of onsite nurse mentoring in improving quality of institutional births in the primary health Centres of high priority districts of Karnataka, South India: a cluster randomized trial. PLoS One. 2016. https://doi.org/10. 1371/journal.pone.0161957.

18. Ameh CA, Kerr R, Madaj B, Mdegela M, Kana T, Jones S, et al. Knowledge and skills of healthcare providers in sub-Saharan Africa and Asia before and after competency-based training in emergency obstetric and early newborn care. PLoS One. 2016. https://doi.org/10.1371/journal.pone.0167270.

19. Lentz GM, Mandel LS, Lee D, Gardella C, Melville J, Goff BA. Testing surgical skills of obstetric and gynecologic residents in a bench laboratory setting: validity and reliability. Am J Obstet Gynecol. 2001;184:1462-8 discussion 1468-70.

20. Macedonia CR, Gherman RB, Satin AJ. Simulation laboratories for training in obstetrics and gynecology. Obstet Gynecol. 2003;102:388-92.

21. Merien AER, van de Ven J, Mol BW, Houterman S, Oei SG. Multidisciplinary team training in a simulation setting for acute obstetric emergencies: A systematic review. Obstet Gynecol. 2010. https://doi.org/10.1097/AOG. Ob013e3181d9f4cd.

22. Amatullah AF. Using interprofessional simulation-based training to improve management of obstetric emergencies: A systematic review. Clinical Simulation Nursing. 2018. https://doi.org/10.1016/j.ecns.2017.10.014.

23. Austin A, Gulema $H$, Belizan M. Barriers to providing quality emergency obstetric care in Addis Ababa, Ethiopia: healthcare providers' perspectives on training, referrals and supervision, a mixed methods study. BMC Pregnancy Childbirth. 2015;15(1):1.

24. Graham W, Bell J, Bullough C. Can skilled attendance at delivery reduce maternal mortality in developing countries? In: De Brouwere $V$, van Lerberghe W, editors. Safe motherhood strategies: a review of the evidence. Antwerp: ITG Press; 2001. p. 97-129.

\section{Publisher's Note}

Springer Nature remains neutral with regard to jurisdictional claims in published maps and institutional affiliations.
Ready to submit your research? Choose BMC and benefit from:

- fast, convenient online submission

- thorough peer review by experienced researchers in your field

- rapid publication on acceptance

- support for research data, including large and complex data types

- gold Open Access which fosters wider collaboration and increased citations

- maximum visibility for your research: over $100 \mathrm{M}$ website views per year

At BMC, research is always in progress.

Learn more biomedcentral.com/submissions 